\title{
PENYULUHAN LITERASI MEDIA TENTANG HOAX DI KALANGAN GENERASI MUDA DESA JUWOK
}

\author{
Sri Herwindya Baskara Wijaya \\ Prodi D3 Komunikasi Terapan Sekolah Vokasi Universitas Sebelas Maret \\ Jl. Ir. Sutami 36A Jebres, Kota Surakarta, Jawa Tengah \\ Email : herwindya82@gmail.com
}

\begin{abstract}
The world is currently entering a new era where information has become one of the main streams of the pendulum of world civilization. This condition has gradually formed an information society where information is the main commodity. Increasing information does not always have a positive effect on society, especially the younger generation. One of them is the prevalence of false information or hoaxes (hoax), especially in the realm of cyberspace. Not only being deceived by fake news, the hoax phenomenon also has implications for horizontal conflict. As an effort to respond to this problem, community service is carried out in the form of media literacy counseling about hoaxes in Juwok Village, Sukodono District, Sragen Regency, Central Java. This service is one of the implementations of the Real Work Lecture (KKN) work program held by Sebelas Maret University (UNS) Surakarta for the January-February 2020 period. Participants in the activity are the young generation in the village related to the activity method consisting of presentations and questions and answers. Presentations using PPT and videos containing material and examples of hoaxes on the internet and social media. The results of this activity are very important to equip the participants about media literacy so that they can wisely access social media, be careful about hoaxes and not get caught up in spreading or even producing hoaxes.
\end{abstract}

Keywords: Media literacy, counseling, internet, social media, hoax

\begin{abstract}
Abstrak: Dunia saat ini sedang memasuki era baru dimana informasi menjadi salah satu arus utama pendulum peradaban dunia. Kondisi ini lambat laun membentuk masyarakat informasi dimana informasi menjadi komoditas utama. Meningkatnya informasi ternyata tidak selalu berefek positif bagi masyarakat terutama generasi muda. Salah satunya adalah maraknya informasi bohong atau hoaks (hoax) terutama menjangkiti ranah dunia maya. Bukan hanya tertipu dengan kabar bohong, fenomena hoaks itu juga bahkan berimplikasi pada konflik horizontal. Sebagai salah satu upaya merespons masalah itu, maka dilakukan pengabdian kepada masyarakat berupa penyuluhan literasi media tentang informasi bohong (hoax) di Desa Juwok, Kecamatan Sukodono, Kabupaten Sragen, Jawa Tengah. Pengabdian ini merupakan salah satu implementasi program kerja Kuliah Kerja Nyata $(\mathrm{KKN})$ yang digelar Universitas Sebelas Maret (UNS) Surakarta periode Januari-Februari 2020. Peserta kegiatan adalah generasi muda di desa terkait dengan metode kegiatan terdiri atas presentasi dan tanya jawab. Presentasi menggunakan PPT dan video berisi materi serta contoh-
\end{abstract}


contoh hoaks di internet dan media sosial. Hasil kegiatan ini sangat penting untuk membekali para peserta tentang literasi media agar mereka bijak mengakses media sosial, bisa berhati-hati soal hoaks dan tidak terjebak menyebarkan atau bahkan memproduksi hoaks.

Kata kunci: Literasi media, penyuluhan, internet, media sosial, hoaks

aat ini, segala sesuatu beranjak ke arah media digital. Interaksi langsung di $\checkmark$ masyarakat semakin berkurang tergantikan dengan interaksi dengan menggunakan media internet. Teknologi pintar dianggap sebagai pendekatan baru dalam perkembanganilmu pengetahuan dan juga pembangunan perdamaian.Media baru mulai dikembangkan sebagai bagian dari teknologi pintar untuk menjawab kemajuan zaman (Vanel, 2019: xii). Internet adalah kata kunci penting dan basis utama kehadiran era digital. Penemuan internet tidak dapat dimungkiri telah membawa perabadan manusia ke arah yang semakin modern, canggih dan praktis. Batasruang dan waktu yang selama beberapa dekade sebelumnya menjadi halangan utama, semisal, dalam hal berkomunikasi kini menjadi runtuh dan luruh. Orang-orang dari berbagai penjuru dunia kini dapat terkoneksi satu sama lain dengan sangat cepat, murah dan mudah (Alkhajar, 2019: xvii).

Kondisi tersebut sebenarnya pernah diramalkan seorang ahli komunikasi Kanada, Herbert Marshall McLuhan (1911-1980) pada paruh pertama dekade 1960-an. Dalam bukunya yang berjudul Understanding Media: The Extensions of Man, ia menulis, "Today, after more than a century of electric technology, we have extended our central nervous system itself in a global embrace, abolishing both space and time as far as our planet is concerned" (McLuhan, 1964, dalam Komisi Komsos KWI, 2018: 11). Pemikirannya dikenal dengan sebutan global village, yang meramalkan adanya world wide web (www). Semua orang saling terhubung dan berjejaring dengan pola komunikasi dua arah, mudah dan murah, serta melibatkan banyak orang. Oleh karena itu, jarak dan waktu menjadi relatif dalam dunia internet seperti zaman sekarang (Komisi Komsos KWI, 2018: 11-12).

Namun, media sendiri (seperti internet dan media sosial) ibarat dua sisi mata pedang, tergantung dari bagaimana kita mempergunakan media tersebut. Internet merupakan salah satu bentuk media baru yang memiliki pengaruh besar dalam pergeseran nilai-nilai sosial di masyarakat. Internet mampu memberikan banyak informasi kepada pemakainya, baik itu informasi positif atau pun negatif, tergantung dari penggunanya (Vanel, 2019: xii).Fenomena Medsosisasi (juga internetisasi) di Indonesia dinilai banyak 
pihak mengalami kesenjangan yaitu antara penggunaan teknologi komunikasi berpiranti Medsos dengan konten (pesan) yang disampaikan. Di satu sisi para netizen diacungi jempol dalam mengoperasikan piranti-piranti canggih teknologi komunikasi berkoneksi Medsos terutama telepon pintar (smartphone) dan komputer. Namun di sisi lain sebagian produk-produk pesan dalam Medsos dinilai mengalami disorientasi etika (Wijaya, 2017).

Meningkatnya penggunaan internet dan media sosial di masyarakat baik global maupun domestik Indonesia ternyata diikuti dengan sisi-sisi negatif, selain aspek-aspek positif, salah satunya adalah informasi palsu atau hoaks (hoax). Hoaks saat ini menjadi salah satu 'penyakit utama' dari efek dunia maya yang penetrasinya dari waktu ke waktu kian meningkat seiring peningkatan penggunaan internet dan media sosial itu sendiri. Kecanggihan teknologi komunikasi dan penguasaan keterampilan teknis penggunaan teknologi terkait ternyata tidak berbanding lurus dengan kompetensi etis di kalangan sebagian netizen (Wijaya, 2019).

Ibarat pisau bermata dua, internet termasuk media sosial, di satu sisi berisi dan mengajarkan berbagai hal-hal positif yang berguna bagi peradaban manusia. Namun di sisi lain, internet termasuk media sosial bermuatan dan menumpahkan berbagai konten negatif kepada publik luas hingga dampaknya sangat terasa dan tidak mudah diurai benang solusinya. Itulah yang disebut kejahatan dunia maya (cyber crime) yang tipologinya sangat membentang luas secara online dari terorisme, radikalisme, hoaks, ujaran kebencian, perundungan,hingga plagiatisme. Inilah pula yang dilabeli era disrupsi dimana tidak sedikit orang yang terdampak secara negatif dari kehadiran teknologi internet dan media sosial. Tatkala internet dan media sosial belum hadir di dunia, maka crime hanya melingkupi di dunia nyata. Namun ketika internet dan media sosial hadir, crime pun juga ikut bersemarak di dunia maya, selain tetap berhiruk pikuk di dunia nyata sendiri (Satyawan, 2019: xxi).

Akhirnya yang terjadi, produksi hoaks makin menjamur baik netizen paham atau tidak paham dalam memproduksinya. Selain tidak benar-benar membaca konten yang dibagikan tetapi percaya kepada sumber yang diyakini dan tidak mempercayai sumber lain, hoaks terjadi dan tersebar karena malas berfikir atau verifikasi, terburu-buru membagikan kabar yang dianggap terhubung, melegitimasi kabar dari seberapa sering kabar itu muncul dan tidak bisa membedakan antara satir dengan hoaks. 
Persebarannya bersifat sporadis dan tidak mudah diredam karena langsung bersentuhan dengan individu-individu netizen di ruang-ruang privasi. Konten-konten hoaks pun beragam mulai dari info ringan kesehatan hingga info berat bernuansa suku, agama, ras dan antargolongan (SARA). Efek dari hoaks pun mengkhawatirkan terutama hoaks yang bernuansa SARA karena bisa menyulut emosi publik dan memantik potensi konflik horizontal. Kondisi ini makin diperparah dengan umpan balik negatif berupa komentar bernuansa ujaran kebencian (hate speech) sehingga makin meruyamkan keadaan (Wijaya, 2019: 59).

Hoaks sendiri dapat didefinisikan sebagai informasi yang direkayasa, baik dengan cara memutarbalikkan fakta atau pun mengaburkan informasi, sehingga pesan yang benar tidak dapat diterima seseorang. Perkembangan penetrasi internet di Indonesia membuat platform media sosial seperti Facebook, Twitter, WhatsApp, Instagram, dan lainnya menjadi sarana efektif untuk mendistribusikan hoaks (PUSAD Paramadina \& Mafindo, 2018: 2).Sementara menurut Kamus Besar Bahasa Indonesia (KBBI), hoaks adalah tidak benar, bohong.Secara umum hoaks adalah berita palsu atau bohong yang tidak dapat dipertanggungjawabkan kebenarannya.

Sejak pertengahan tahun 2014 secara berangsur-angsur meningkat, masyarakat dihebohkan dengan munculnya banyak sekali informasi- informasi di media sosial yang bersifat hoax. Gelombang mengemukanya fenomena berita-berita hoax, berita yang diada-adakan alias palsu di berbagai media, terutama media sosial terjadi pada tahun 2016 lalu. Saking menonjolnya berita hoax, banyak yang berspekulasi bahwa kita hidup dalam masyarakat di mana kejujuran bertindak dan kejernihan berpikir telah hilang.Sebaliknya, saling tidak percaya dan curiga menjadi sesuatu yang wajar (Ambara, 2017, dalam Ali, 2017: 190).

Selain tidak benar-benar membaca konten yang dibagikan tetapi percaya kepada sumber yang diyakini dan tidak mempercayai sumber lain, hoaks terjadi dan tersebar karena malas berfikir atau verifikasi, terburu-buru membagikan kabar yang dianggap terhubung, melegitimasi kabar dari seberapa sering kabar itu muncul dan tidak bisa membedakan antara satir dengan hoaks. Persebarannya bersifat sporadis dan tidak mudah diredam karena langsung bersentuhan dengan individu-individu netizen di ruang-ruang privasi. Konten-konten hoaks pun beragam mulai dari info ringan kesehatan hingga info berat bernuansa suku, agama, ras dan antargolongan (SARA). Efek dari hoaks pun 
mengkhawatirkan terutama hoaks yang bernuansa SARA karena bisa menyulut emosi publik dan memantik potensi konflik horizontal. Kondisi ini makin diperparah dengan umpan balik negatif berupa komentar bernuansa ujaran kebencian (hate speech) sehingga makin meruyamkan keadaan (Wijaya, 2019: 59; Wijaya, 2020).

Berdasarkan latar belakang di atas maka penting sekali dilakukan pemberdayaan terhadap masyarakat terutama generasi muda dalam menggunakan internet dan media sosial secara bijak. Melalui penyuluhan mengenai literasi media, diharapkan mereka dapat menjadi netizen yang baik, tidak tertipu oleh hoaks juga tidak memproduksi hoaks. Termasuk dalam hal ini adalah generasi muda di Desa Juwok, Kecamatan Sukodono, Kabupaten Sragen yang tidak sedikit juga mengakses internet dan media sosial terutama melalui ponsel pintar (smart phone). Kegiatan ini sendiri sebagai bagian dari dari program kerja (Proker) Kuliah Kerja Nyata (KKN) Universitas Sebelas Maret (UNS) Surakarta periode Januari-Februari 2020.

Desa Juwok merupakan salah satu wilayah di Kecamatan Sukodono, Kabupaten Sragen, Provinsi Jawa Tengah. Meski secara geografis berada di pinggiran utara dari pusat kota, namun akses informasi di desa ini cukup bagus. Salah satunya ditandai oleh banyaknya warga terutama kalangan generasi muda yang mengakses internet terutama melalui ponsel. Kegiatan penyuluhan ini sendiri merupakan bagian dari program kerja (Proker) Kuliah Kerja Nyata (KKN) Universitas Sebelas Maret (UNS) Surakarta periode Januari-Februari 2020.

Berdasarkan latar belakang masalah di atas, maka rumusan masalah yang dikemukakan adalah bagaimana deskripsi pelaksanaan kegiatan penyuluhan tentang literasi media terkait kabar bohong (hoax) di kalangan generasi muda Desa Juwok, Kecamatan Sukodono, Kabupaten Sragen, Jawa Tengah. Adapun tujuan dari kegiatan ini adalah membekali kalangan generasi muda Desa Juwok, Kecamatan Sukodono, Kabupaten Sragen mengenai literasi media terkait kabar bohong (hoax) agar mereka dapat bijak dalam mengakses media sosial, diharapkan mereka dapat menjadi netizen yang baik, tidak tertipu oleh hoaks juga tidak memproduksi hoaks.

\section{METODE PELAKSANAAN}

Pengabdian kepada masyarakat ini berupa penyuluhan secara terarah kepada generasi muda di Desa Juwok, Kecamatan Sukodono, Kabupaten Sragen yang berjumlah 
sekitar 20-an orang. Para peserta berasal dari beragam latar belakang mulai pelajar, mahasiswa, wirausahawaan maupun aktivis desa. Metode yang diterapkan dalam kegiatan ini terdiri atas metode presentasi dan metode diskusi. Metode presentasi berupa penyampaian materi penyuluhan melalui power point (ppt) dan video. Metode diskusi berupa tanya jawab antara pemateri dengan para peserta tentang materi yang disampaikan.

\section{HASIL DAN PEMBAHASAN}

Kegiatan penyuluhan ini dilaksanakan pada Minggu, 18 Februari 2020 bertempat di Balai Desa Juwok, Kecamatan Sukodono, Kabupaten Sragen. Beberapa pemateri yang hadir adalah tim dosen dari FISIP UNS dan Sekolah Vokasi UNS antara lain Drs. Ign. Agung Satyawan, SE. SIkom. MSi. PhD., Dra. Christina Tri Hendriyani, MSi., Sri Herwindya Baskara Wijaya, S.Sos. MSi., dan Firdastin Ruthnia Yudiningrum, S.Sos. MSi. Kegiatan berlangsung selama kurang lebih dua jam dengan sejumlah materi pokok yakni definisi hoaks, batasan hoaks, jenis-jenis hoaks, contoh-contoh hoaks, regulasi tentang hoaks serta cara mengidentifikasi hoaks. Beberapa materi ini disampaikan secara bergantian oleh tim pemateri.

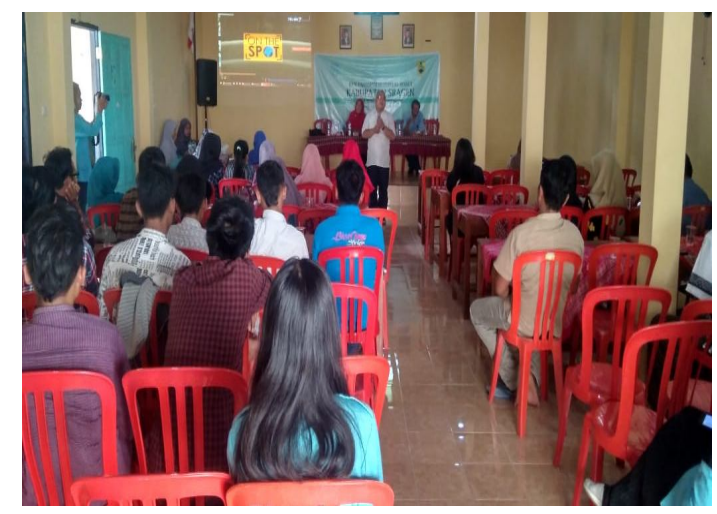

\section{Gambar 1. Penyuluhan Literasi Media tentang Hoaks di Desa Juwok}

Sumber : Dokumentasi Pengabdian Masyarakat

Dalam pemaparannya, pemateri menyampaikan bahwa hoaks sebagai informasi yang tidak benar dan cenderung dibuat dengan sengaja, tersebar melalui berbagai saluranterutama internet dan media sosial, isinya beragam, bisa membuat kecemasan serta sebagian isi hoaks sulit diidentifikasi. Pandangan para pemateri ini sejalan dengan temuan survei dari Masyarakat Telematika Indonesia (Mastel) dan Tanpa Hoax Indonesia 
Sejahtera (THIS) tahun 2019 terhadap masyarakat Indonesia. Hasil survei ini menemukan pandangan responden yang menilai bahwa hoaks sebagai berita bohong yang disengaja $(88 \%)$, berita yang menghasut $49 \%$, berita yang tidak akurat $61 \%$, berita ramalan/fiksi ilmiah $15 \%$, berita yang menyudutkan pemerintah $14 \%$, berita yang menjelekkan orang lain $31 \%$, berita yang tidak saya sukai $3 \%$, dan tidak tahu $1 \%$.

Selain itu, hasil survei Mastel dan THIS ini juga menemukan hoaks di berbagai saluran seperti sosial media $87,50 \%$, aplikasi chatting $67 \%$, website $28,20 \%$, media cetak $6,40 \%$, email $2,60 \%$, televisi/radio $8,10 \%$.Jenis isi hoax yang sering diterima responden antara lain info pekerjaan $24,20 \%$, kecelakaan lalu lintas $13,50 \%$, bencana alam $29,30 \%$, sosial budaya $18,10 \%$, candaan $0 \%$, berita duka $16,80 \%$, Iptek $20 \%$, penipuan keuangan 18,5\%, makanan dan minuman 30\%, kesehatan 40\%, pemerintahan $61,70 \%$, SARA $76,20 \%$, sosial-politik 93,20\%. Ragam bentuk hoax yang sering diterima responden antara lain tulisan $70,7 \%$, foto editan $57,8 \%$, foto dengan caption palsu $66,3 \%$, video editan (dubbing palsu) 33,2\%, video editan (dipotong-potong) 45,70\%, video dengan caption/narasi palsu 53,2\%, berita/foto/video lama diposting kembali 69,20\% (Mastel \& THIS, 2019; Wijaya, 2019: 79).

Selain itu, hoaks sampai batas tertentu juga bisa menimbulkan kecemasan. Hal ini sesuai dengan hasil survei Edelman Trust Barometer 2018 yang menemukanbahwa tujuh dari 10 masyarakat dunia merasa khawatir jika berita palsu akan digunakan sebagai "senjata". Di Indonesia sendiri, 76\%-80\% masyarakat khawatir akan pemanfaatan hoaks sebagai senjata untuk menciptakan ketidakstabilan dalam negeri. Kekhawatiran masyarakat ini tak lepas dari sebaran hoaks yang semakin cepat melalui media sosial. Sebagai pengguna aktif media sosial maupun aplikasi pesan, masyarakat Indonesia rentan menerima informasi yang tidak tepat (tirto.id, 17/5/2018). Sebagian masyarakat termasuk para peserta penyuluhan ternyata juga mengalami kesulitan dalam mengidentifikasi ciriciri hoaks. Hal ini karena mereka memang merasa kesulitan membedakan sebagian informasi kategori hoaks atau tidak. Soal ini sejalan dengan riset Mastel dan THIS tahun 2019 yang menyebutkan masyarakat Indonesia menilai sulit mengidentifikasi ciri-ciri hoaks 21,80\% dan sangat sulit 3,40\% (Mastel \& THIS, 2019).

Mengenai pandangan bahwa sebagian hoaks tidak mudah diidentifikasi, tim pemateri dalam penyuluhan terkait menyampaikan ciri-ciri hoaks disertai dengan contohcontohnya yang muncul di internet atau media sosial. Adapun diantara ciri-ciri 
hoakstersebut adalah sumber berita tidak jelas, merasa ada yang aneh,tidak diberitakan media massa, to good to be true (terlalu sempurna untuk terjadi), sebagian terdapat tanda panah atau lingkaran merah, menggunakan judul berita yang spektakuler, menggunakan alamat website yang mirip dengan media besar, menggunakan unsur mencocokcocokkan/memaksakan.

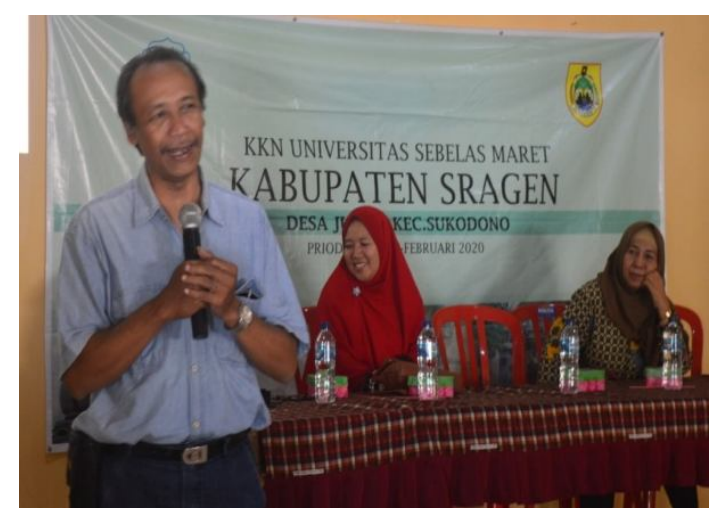

\section{Gambar 2. Pemateri Menyampaikan Materi tentang Hoaks}

Sumber : Dokumentasi Pengabdian Masyarakat

Selain itu, ciri hoaks menurut para pemateri penyuluhan ini adalah isi informasi bisa mengakibatkan kecemasan, kebencian dan permusuhan (fear arousing),pemberitaannya tidak berimbang (not balance), cenderung menyudutkan pihak tertentu (onesided), bermuatan fanatisme atas nama ideologi (plain folks), judul dan pengantarnya provokatif(isi berita), memberikan 'pembenaran',menyembunyikan fakta/data sebenarnya, sebagian mencatut nama tokoh tertentu (transfer device), meminta isi dibagikan kembali (band wagon),memberi julukan tertentu (name calling), menggunakan data yang "sangat ilmiah" agar dipercaya (card stacking),memelintir pernyataan pihak tertentu, manipulasi foto/gambar/video dan keterangan penjelasnya, jika sudah ada klarifikasi atau diberitakan di pers arus utama (mainstream) maka itu hoaks.

Kegiatan ini sendiri berjalan lancar dan sukses. Selain dilihat dari jumlah peserta yang hadir, kesuksesan ini juga bisa dilihat dari antuasias para peserta mengikuti kegiatan seperti ketika sesi diskusi dimana para peserta banyak memberikan respons positif. Dengan ditampilkan banyak contoh hoaks yang beredar di media sosial baik video maupun foto menjadikan para peserta lebih paham mengenai hoaks. Meski berjalan lancar, namun belum sepenuh materi bisa disampaikan oleh para pemateri mengingat waktu pelaksanaan kegiatan yang terbatas. 


\section{SIMPULAN}

Ada beberapa simpulan yang dapat ditarik dari kegiatan ini:

1. Penyuluhan literasi media terkait kabar bohong (hoax) di kalangan generasi muda Desa Juwok, Kecamatan Sukodono, Kabupaten Sragen ini merupakan kegiatan pengabdian kepada masyarakat sebagai bagian dari program kerja Kuliah Kerja Nyata (KKN) UNS periode Januari-Februari 2020.

2. Hasil yang didapat dari kegiatan ini adalah pemahaman tentang kabar bohong atau hoaks baik konsep maupun praktiknya di lapangan sehingga para peserta dapat bersikap bijak dalam mengakses internet/media sosial.

3. Kelebihan kegiatan ini adalah mampu menambah wawasan para peserta mengenai hoaks sehingga dapat lebih berhati-hati jika menerima informasi di internet/media sosial sekaligus tidak terjebak ikut menyebarkan/memproduksi hoaks.

4. Kekurangan kegiatan ini adalah belum tersampaikannya materi secara tuntas mengingat keterbatasan waktu.

5. Diharapkan kegiatan serupa dapat dilanjutkan lagi dengan materi lebih mendalam dan peserta lebih banyak dan beragam termasuk kalangan anak-anak dan orangtua.

\section{DAFTAR PUSTAKA}

Ali, M. 2017. 'Antara Komunikasi, Budaya dan Hoax'. Melawan Hoax di Media Sosial dan Media Massa. Yogyakarta: Trustmedia Publishing

Alkhajar, E.N.S. (2019). "Literasi Media Baru, Ketidakberpikiran dan Esensi Kemanusiaan Di Era Digital”. Seri Literasi Media: Dari Hoax hingga Hacking. Yogyakarta: Buku Litera.

Departemen Pendidikan Nasional. (2002). Kamus Besar Bahasa Indonesia. Edisi ke-3. Jakarta : Gramedia.

Gerintya, S. (2018). Hoaks dan Bahaya Rendahnya Kepercayaan terhadap Media, www.tirto.id.

Mastel dan THIS. 2019. Hasil Survei Wabah Hoax Nasional. www.mastel.id, PPT.

Pusat Studi Agama dan Demokrasi (PUSAD) dan Yayasan Paramadina Masyarakat Anti Fitnah Indonesia (Mafindo). (2019). Buku Panduan Melawan Hasutan Kebencian. Jakarta: PUSAD dan Mafindo bekerjasama dengan International Foundation for Electoral System (IFES).

Satyawan, I. A. (2019). "Meliterasi Publik di Tengah Paradoksial Informasi”. Seri Literasi Media: Dari Hoax hingga Hacking. Yogyakarta: Buku Litera. 
Tim Komisi Komsos Konferensi WaliGereja Indonesia (KWI). (2018).Pedoman Penggunaan Media Sosial. http://www.mirifica.net/wpcontent/ uploads/2018/07/NASKAH-PEDOMAN-PENGGUNAANMENSOS.pdf.,

Vanel, Z. (2019). "Peran Teknologi Pintar dalam Pembangunan Perdamaian". Seri Literasi Media: Dari Hoax hingga Hacking. Yogyakarta: Buku Litera.

Wijaya, S.H.B. (2019a). Seri Literasi Media: Dari Hoax hingga Hacking. Yogyakarta: Buku Litera.

Wijaya, S.H.B. (2019b).Bersikap Bijak dalam Bermedsos. Koran Sebelas Maret. Edisi Maret 2017.

Wijaya, S.H.B. dan Alkhajar, E.N.S. (2020). MemotretPandemi COVID-19: Hoax dan Paradoks Kemanusiaan. Yogyakarta: Buku Litera. 